\title{
GAMBARAN SITUASI SUMBER DAYA MANUSIA KESEHATAN (SDMK) DI PROVINSI JAWA TIMUR TAHUN 2015
}

\author{
DESCRIPTION OF HEALTH HUMAN RESOURCES SITUATION (SDMK) \\ IN EAST JAVA PROVINCE 2015
}

\author{
Elza Nur Fitriyah \\ Fakultas Kesehatan Masyarakat, Universitas Airlangga, Surabaya \\ Alamat Korespondensi: \\ Elza Nur Fitriyah \\ E-mail: elzafitriah@gmail.com
}

\begin{abstract}
Based on WHO (2006) health workers have been contributed until $80 \%$ in health development. The determination of health human resources development (SDMK) as one priorities for Indonesia which still having problem workforce, both in terms of the kind of quality as well as distribution. The Ratio of SDMK of 100.000 populations does not achieve the target. The purpose of this study was to know the condition of SDMK in Province East Java 2015. The study design is cross sectional which using secondary data. The Subject in this study is SDMK data 2015 in Province East Java Health Ministry. Data analysis using descriptive analysis was used to analyze the data to describe the situation of SDMK in Provice East Java 2015. The results showed that SDMK amount as follows: specialist doctors 6.716, doctors 6.460 , dentists 2.178, midwifes 7.664, nurses 33.050, public healths 1.410, sanitarians 446, pharmacists 3.131, nutritionists 608 and physical terapys 1.113. The conclusion is almost SDMK in Province East Java 2015 are doctors, midwifes and nurses. SDMK equalization has not fully happened, they are avalaible in major cities while in other cities tend to be less. The Ratio SDMK 2015 does not achieve the Health Ministry target although there are several types of SDMK are close to the target. The Health Ministry could be obtained to optimize the equalizaton of SDMK in the district/city in order to be equitable distribution to improve health services to the community.
\end{abstract}

Keywords: describe, situation, health human resources(SDMK), Province East Java 


\section{ABSTRAK}

Menurut WHO (2006) tenaga kesehatan memberikan kontribusi hingga 80\% dalam pembangunan kesehatan. Penetapan pengembangan sumber daya manusia kesehatan (SDMK) sebagai salah satu prioritas karena Indonesia masih menghadapi masalah ketenagaan, baik dari jumlah, jenis, kualitas maupun distribusinya. Rasio SDMK per 100.000 penduduk belum memenuhi target yang ditetapkan (WHO, 2011). Penelitian ini bertujuan untuk mengetahui gambaran situasi SDMK di Provinsi Jawa Timur Tahun 2015. Desain penelitian ini adalah cross sectional menggunakan data sekunder. Subjek dalam penelitian ini adalah data SDMK tahun 2015 di Dinas Kesehatan Provinsi Jawa Timur. Analisis deskriptif digunakan dalam menganalisis data untuk menggambarkan situasi (SDMK) di Provinsi Jawa Timur tahun 2015. Hasil penelitian ini menunjukkan jumlah SDMK sebagai berikut : jumlah dokter spesialis sebanyak 6.716, dokter umum sebanyak 6.460, dokter gigi sebanyak 2.178 , bidan sebanyak 7.664, perawat sebanyak 33.050, tenaga kesehatan masyarakat sebanyak 1.410, tenaga kesehatan lingkungan sebanyak 446, tenaga kefarmasian sebanyak 3.131, tenaga gizi 608 dan jumlah tenaga keterapian fisik sebanyak 1.113. Kesimpulannya jumlah SDMK di Jawa Timur tahun 2015 paling banyak adalah dokter, bidan dan perawat. Pemerataan SDMK belum seluruhnya terjadi, sumber daya manusia kesehatan lebih banyak didapatkan di kota - kota besar sedangkan di kota lainnya cenderung lebih sedikit. Rasio SDMK pada tahun 2015 masih dibawah target Kepmenkes meski terdapat beberapa jenis SDMK yang mendekati target. Bagi instansi terkait diharapkan dapat mengoptimalkan upaya pemerataan sumber daya manusia kesehatan (SDMK) di kabupaten/kota agar distribusinya dapat merata sehingga diharapkan dapat meningkatkan pelayanan kesehatan terhadap masyarakat.

\section{Kata Kunci : gambaran, situasi, sumber daya manusia kesehatan (SDMK), Provinsi Jawa} Timur

\section{PENDAHULUAN}

Pembangunan kesehatan adalah upaya yang dilaksankan oleh semua komponen bangsa dalam rangka meningkatkan kesadaran, kemauan dan kemampuan hidup sehat bagi setiap orang. Penyelenggaraan pembangunan kesehatan mengacu kepada Sistem Kesehatan Nasional (SKN) dengan 6 subsistem, diantaranya adalah subsistem sumber daya manusia (SDM) kesehatan. Tujuan dari subsistem ini agar tersedia SDMK yang kompeten sesuai kebutuhan, terdistribusi secara adil dan merata serta didayagunakan secara optimal dalam mendukung subsistem - subsistem kesehatan lainnya (Depkes, 2009). Menurut WHO (2006) tenaga kesehatan memberikan kontribusi hingga $80 \%$ dalam keberhasilan pembangunan kesehatan.

SDMK adalah seseorang yang aktif bekerja di bidang kesehatan baik berpendidikan formal kesehatan maupun tidak dan dalam jenis tertentu memerlukan kewenangan dalam melakukan upaya kesehatan (Kepmenkes, 2008). Tenaga kesehatan yang merupakan bagian dari SDMK terdiri dari tenaga medis, tenaga keperawatan, tenaga kefarmasian, tenaga kesehatan masyarakat, tenaga gizi, tenaga keterapian fisik dan keteknisisan medis (Dinas Kesehatan Provinsi Jawa Timur, 2014).

Pengembangan sumber daya manusia merupakan salah satu fokus prioritas pembangunan kesehatan dalam kurun waktu 2010 - 2014. Penetapan pengembangan SDMK sebagai salah satu prioritas karena Indonesia masih mengahadapi masalah tenaga kesehatan baik jumlah, jenis, kualitas maupun distribusinya. Rasio tenaga kesehatan per 100.000 penduduk belum memenuhi target yang ditetapkan sampai tahun 2010 (WHO, 2011).

Rasio dokter umum digunakan sebagai acuan untuk melihat sejauh mana fasilitas kesehatan yang mejadi ujung tombak pembangunan kesehatan masyarakat dapat berfungsi dengan baik. 
Tenaga kesehatan yang mempunyai peran penting dalam pelayanan kesehatan ibu dan anak, terutama pelayanan kesehatan di daerah pedesaan adalah bidan. Selain itu jumlah SDMK lainnya perlu dikaji mengingat perananya cukup besar dalam memberikan pembangunan kesehatan bagi suatu wilayah (Kajian Kebijakan Perencanaan Tenaga Kesehatan, 2005).

Kondisi tenaga kesehatan di Indonesia khususnya dokter, bidan dan perawat sampai dengan tahun 2008, rasio dokter umum per 100.000 penduduk 26,3 dibanding target 30; rasio bidan per 100.000 penduduk 43,75 dibanding target 75 dan rasio perawat per 100.000 penduduk 157,75 dibanding target 158. Sedangkan di Puskesmas pada tahun 2010 telah tersedia 14.840 dokter umum; 83.000 bidan dan 78.675 perawat. Hal ini terlihat bahwa rasio ketiga jenis tenaga kesehatan diatas menunjukkan dibawah target rasio yang ditentukan (RPTK, 2011 - 2025).

Provinsi Jawa Timur merupakan salah satu provinsi yang mempunyai jumlah penduduk tertinggi. Provinsi Jawa Timur menduduki peringkat kedua setelah Provinsi Jawa Barat dengan jumlah penduduk tertinggi di Indonesia. Selain itu, Provinsi Jawa Timur menduduki peringkat ke tiga dengan jumlah tenaga medis terbanyak di Indonesia yaitu sebesar 21.022 tenaga medis (Pusdatin Kemenkes RI, 2014).

Berdasarkan data dari Dinas Kesehatan Provinsi Jawa Timur pada tahun 2014, jumlah tenaga kesehatan dengan proporsi terbesar adalah perawat yaitu 31.830; bidan 16.652 dan dokter umum 6.032 (Dinas Kesehatan Provinsi Jawa Timur, 2014)

Meskipun jumlah dokter, bidan dan perawat mengalami peningkatan setiap tahunnya, namun persebarannya di Kabupaten/Kota masih belum merata. Distribusi tenaga kesehatan yang tidak merata ini merupakan masalah utama dalam pengelolaan tenaga kesehatan, yang sebenarnya dapat diantisipasi dengan perencanaan yang baik (Rasul dan Hasanbari, 2007).
Penelitian ini bertujuan untuk mengetahui gambaran ketersediaan SDMK di Provinsi Jawa Timur Tahun 2015.

\section{METODE PENELITIAN}

Desain penelitian ini adalah cross sectional menggunakan data sekunder. Subjek dalam penelitian ini adalah data tenaga kesehatan tahun 2015 di Dinas Kesehatan Provinsi Jawa Timur.

Penelitian ini dilakukan di Dinas Kesehatan Provinsi Jawa Timur pada bulan september tahun 2016. Sumber data adalah laporan SDMK Tahun 2015 di Dinas Kesehatan Provinsi Jawa Timur.

Analisis deskriptif digunakan dalam menganalisis data untuk menggambarkan situasi sumber daya manusia kesehatan (SDMK) di Provinsi Jawa Timur tahun 2015 .

\section{HASIL DAN PEMBAHASAN}

Berdasarkan data dari Dinas Kesehatan Provinsi Jawa Timur tahun 2015 jumlah dokter spesialsis sebanyak 6.716, dokter umum sebanyak 6.460, dokter gigi sebanyak 2.178, bidan sebanyak 7.664, perawat sebanyak 33.050, tenaga kesehatan masyarakat sebanyak 1.410, tenaga kesehatan lingkungan sebanyak 446, tenaga kefarmasian sebanyak 3.131, tenaga gizi 608 dan jumlah tenaga keterapian fisik sebanyak 1.113 .

Jumlah dokter spesialis menurut kabupaten/kota dapat dilihat pada gambar berikut.

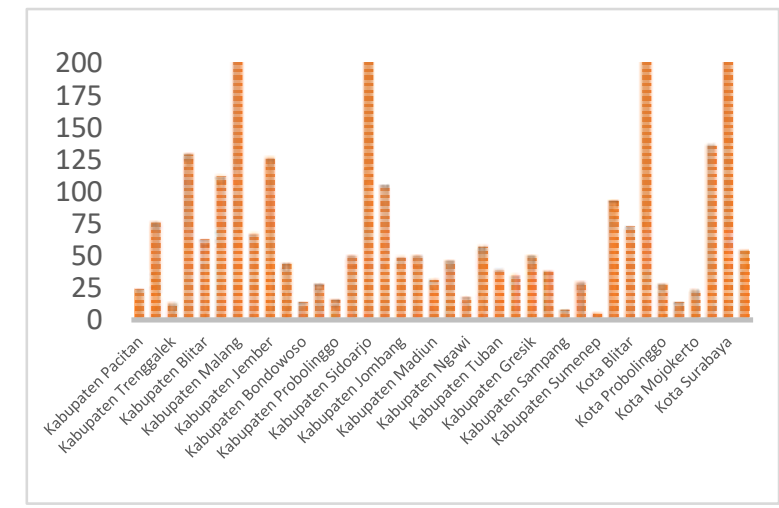

Gambar 1. Jumlah dokter spesialis menurut Kabupaten/Kota di Provinsi Jawa Timur Tahun 2015 
Jumlah dokter spesialis tertinggi dimiliki oleh Kota Surabaya, Kabupaten Sidoarjo dan Kota Malang sedangkan jumlah dokter spesialis terendah dimiliki oleh Kabupaten Sumenep, Kabupaten Sampang dan Kabupaten Trenggalek.

Jumlah dokter umum menurut kabupaten/kota dapat dilihat pada gambar berikut.

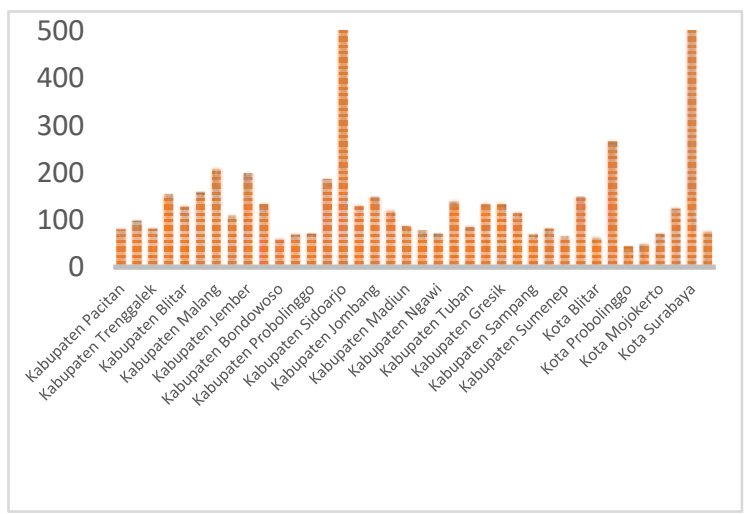

Gambar 2. Jumlah dokter umum menurut Kabupaten/Kota di Provinsi Jawa Timur Tahun 2015

Jumlah dokter umum tertinggi dimiliki oleh Kota Surabaya, Kabupaten Sidoarjo dan Kota Malang sedangkan jumlah dokter terendah dimiliki oleh Kota Probolinggo, Kabupaten Pasuruan dan Kabupaten Bondowoso.

Jumlah dokter gigi menurut kabupaten/kota dapat dilihat pada gambar berikut.

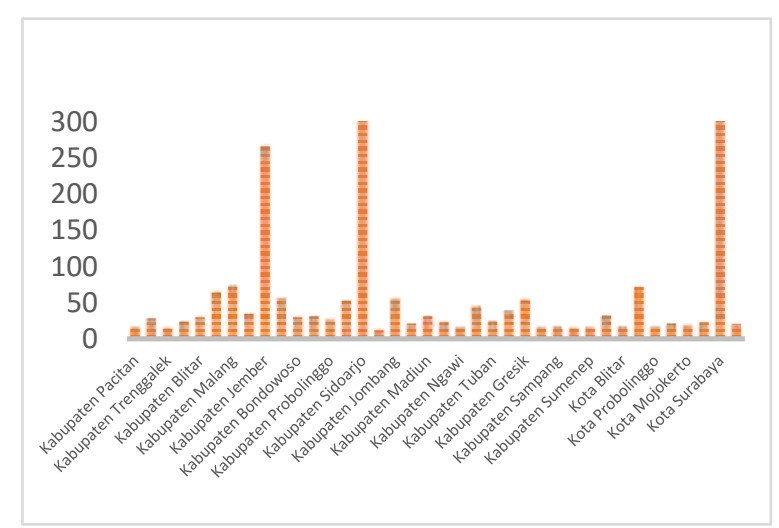

Gambar 3. Jumlah dokter gigi menurut Kabupaten/Kota di Provinsi Jawa Timur Tahun 2015

Jumlah dokter gigi tertinggi dimiliki oleh Kota Surabaya, Kabupaten Sidoarjo dan Kabupaten Jember, sedangkan terendah dimiliki oleh Kabupaten Mojokerto, Kabupaten Trenggalek dan Kabupaten Pamekasan.
Jumlah Bidan menurut kabupaten / kota dapat dilihat pada gambar berikut.

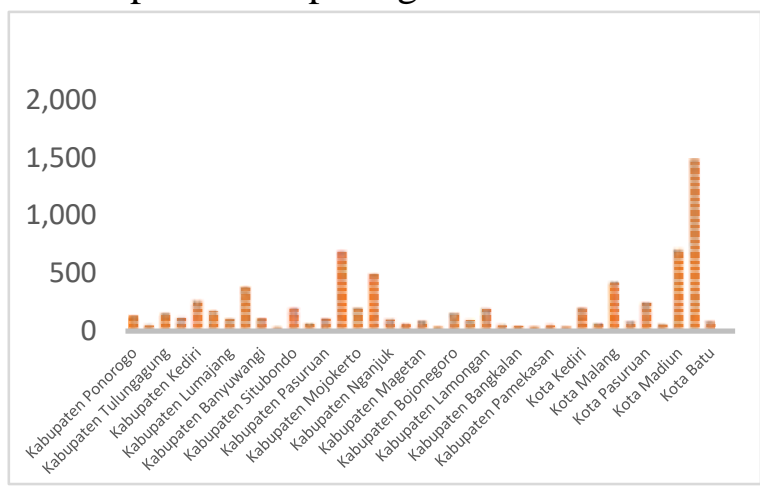

Gambar 4. Jumlah bidan menurut Kabupaten/Kota di Provinsi Jawa Timur Tahun 2015

Jumlah bidan tertinggi dimiliki oleh Kota Surabaya, Kota Madiun dan Kabupaten Sidoarjo sedangkan jumlah bidan terendah dimiliki oleh Kabupaten Bondowoso, Kabupaten Sampang dan Kabupaten Ngawi.

Jumlah Perawat menurut kabupaten/kota dapat dilihat pada gambar berikut.

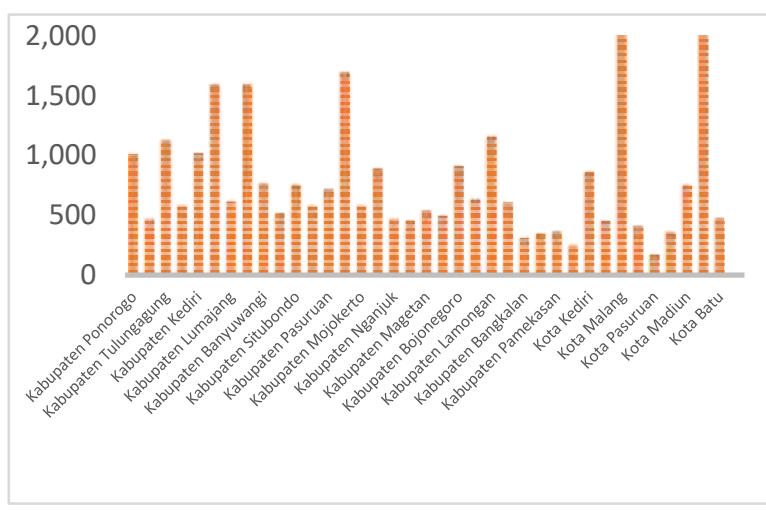

Gambar 5. Jumlah perawat menurut Kabupaten/Kota di Provinsi Jawa Timur Tahun 2015

Jumlah perawat tertinggi dimiliki oleh Kota Surabaya, Kota Malang dan Kabupaten Sidoarjo sedangkan terendah dimiliki oleh Kabupaten Pasuruan, Kabupaten Sumenep dan Kabupaten Bangkalan.

Jumlah kesehatan masyarakat menurut kabupaten/kota dapat dilihat pada gambar berikut. 


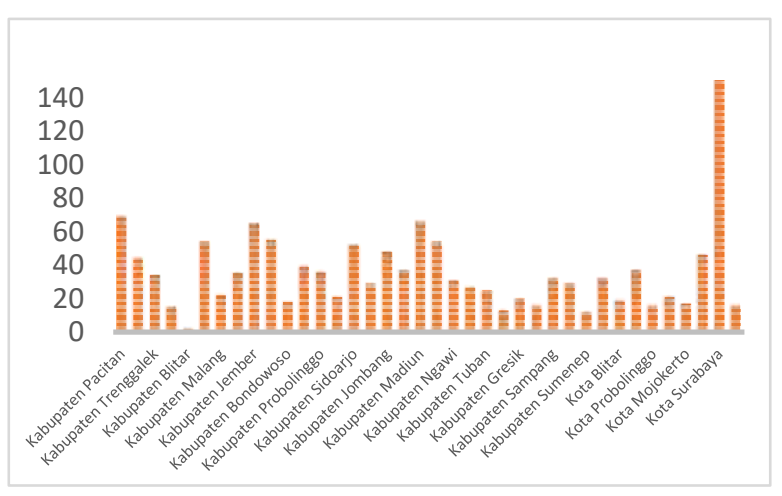

Gambar 6. Jumlah kesehatan masyarakat Menurut Kabupaten/Kota di Provinsi Jawa Timur Tahun 2015

Jumlah tenaga kesehatan masyarakat tertinggi dimiliki oleh Kota Surabaya, Kabupaten Madiun dan Kabupaten Pacitan sedangkan terendah dimiliki oleh Kabupaten Blitar, Kabupaten Sumenep dan Kabupaten Lamongan.

Jumlah tenaga kesehatan lingkungan menurut kabupaten/kota dapat dilihat pada gambar berikut.

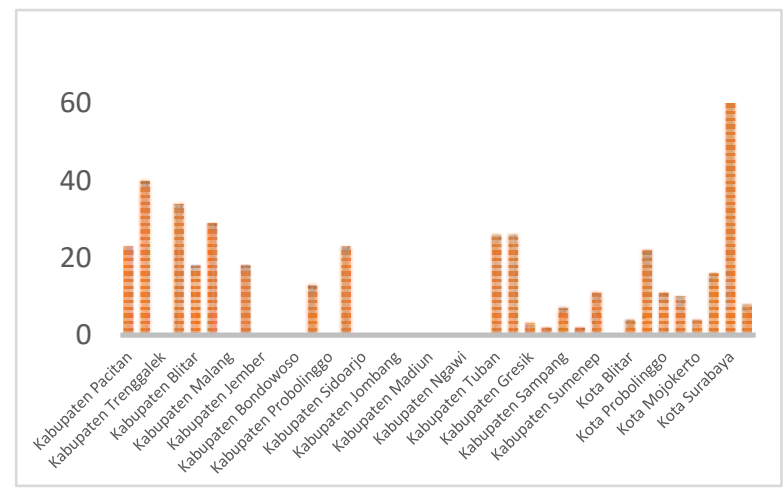

Gambar 7. Jumlah tenaga kesehatan lingkungan menurut Kabupaten/Kota di Provinsi Jawa Timur Tahun 2015

Jumlah tenaga kesehatan lingkungan tertinggi dimiliki oleh Kota Surabaya, Kabupaten Tulungagung dan Kabupaten Ponorogo sedangkan terendah dimiliki oleh 15 kabupaten/kota diantaranya Kabupaten Mojokerto, Kabupaten Ngawi, Kabupaten Bondowoso dan lain sebagainya.

Jumlah tenaga gizi menurut kabupaten/kota dapat dilihat pada gambar berikut.

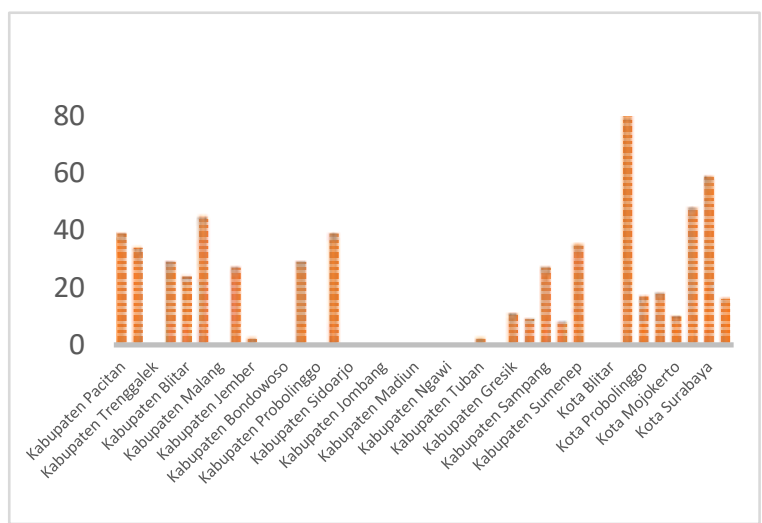

Gambar 8. Jumlah tenaga gizi menurut Kabupaten/Kota di Provinsi Jawa Timur Tahun 2015

Jumlah tenaga gizi tertinggi dimiliki oleh Kota Malang, Kota Surabaya dan Kota Madiun sedangkan terendah dimiliki oleh Kabupaten Mojokerto, Kabupaten Ngawi dan Kabupaten Bondowoso.

Jumlah tenaga kefarmasian menurut kabupaten/kota dapat dilihat pada gambar berikut.

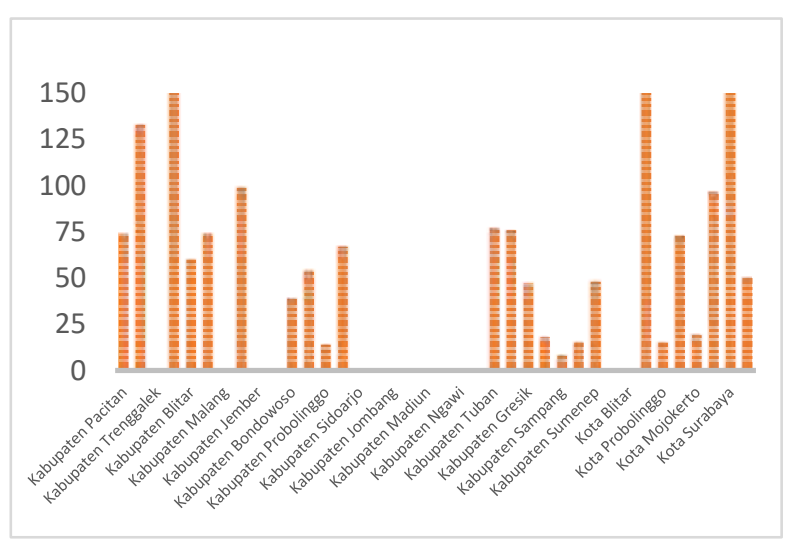

Gambar 9. Jumlah tenaga kefarmasian Menurut Kabupaten/Kota di Provinsi Jawa Timur Tahun 2015

Jumlah tenaga kefarmasian tertinggi dimiliki oleh Kota Surabaya, Kota Malang dan Kabupaten Tulungagung sedangkan terendah dimiliki oleh 14 kabupaten/kota lainnya diantaranya Kabupaten Mojokerto, Kabupaten Ngawi Kabupaten Nganjuk dan lain sebagainya.

Jumlah tenaga keterapian fisik menurut kabupaten/kota dapat dilihat pada gambar berikut. 


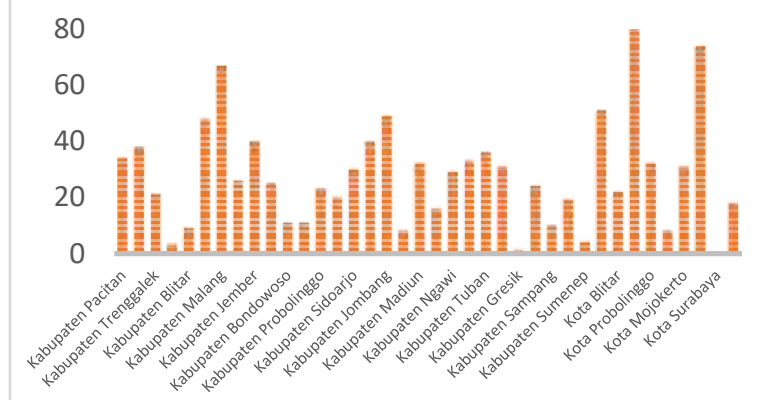

Gambar 10. Jumlah tenaga keterapian fisik menurut kabupaten/kota di Provinsi Jawa Timur Tahun 2015

Jumlah tenaga keterapian fisik tertinggi dimiliki oleh Kota Malang, Kota Madun dan Kabupaten Malang sedangkan Kabupaten Gresik, Kabupaten Tulungagung dan Kabupaten Sumenep.

\section{PEMBAHASAN}

Dari tabel diatas, jelas terlihat bahwa pemerataan SDMK belum seluruhnya terjadi, tenaga kesehatan lebih banyak didapatkan di kota - kota besar seperti Kota Surabaya, Kota Malang dan Kabupaten Sidoarjo sedangkan di Kabupaten Ngawi, Kabupaten Sumenep dan Kabupaten Bondowoso tenaga kesehatan jumlah tenaga kesehatan cenderung lebih sedikit. Terpusatnya tenaga kesehatan di kota dikarenakan laju pertumbuhan ekonomi yang cepat dan tinggi di tiga kota tersebut.

Laju pertumbuhan ekonomi ditunjukkan dengan nilai PDRB yang dimiliki oleh 3 kota/kabupaten tersebut yang tinggi yaitu Kota Surabaya 108.326; Kota Malang 52.093 dan Kabupaten sidoarjo 41.094 (BPS, 2013). Kabupaten/kota yang memiliki nilai PDRB tinggi secara otomatis akan memiliki pendapatan per kapita yang tinggi bagi masyarakat di daerah tersebut, sehingga para tenaga kerja khususnya tenaga kesehatan lebih tertarik untuk bekerja di 3 kota/kabupaten tersebut.

Selain itu, dengan meningkatnya laju pertumbuhan ekonomi di kota/kabupaten tersebut, tersedianya fasilitas seperti pendidikan, kesehatan, sarana rekreasi serta fasilitas lainnya yang lebih lengkap juga akan mendorong tenaga kesehatan lebih memilih untuk bekerja di kota - kota besar.

Namun, hal tersebut berbanding terbalik dengan 3 Kabupaten yang memiliki SDMK yang lebih sedikit dibandingkan dengan kota/kabupaten lain. Tiga Kabupaten ini adalah Kabupaten Ngawi, Kabupaten Bondowoso dan Kabupaten Sumenep. Menurut BPS (2013) Kabupaten Bangkalan dan Kabupaten Sampang tersebut masuk kedalam kuadran II, merupakan daerah dengan pertumbuhan ekonomi di bawah rata - rata provinsi artinya keadaan ekonomi di daerah tersebut kurang baik dibandingkan dengan kabupaten lainnya, dan secara langsung juga akan mempengarui tingkat pendapatan bagi masyarakat yang berada di daerah tersebut. Alasan ini merupakan salah satu penyebab kemungkinan berkurangnya minat tenaga kesehatan untuk bekerja di daerah tertinggal seperti di sana. Selain itu, akses yang sulit dijangkau pada daerah tertinggal dan terpencil juga dapat mempengarui jumlah tenaga kesehatan di wilayah tersebut. Oleh karena itu pemerintah perlu memberikan fasilitas bagi tenaga kesehatan yang berada di daerah tertinggal seperti rumah dinas, kendaraan, insentif serta kemudahan akses dan sarana transportasi agar menarik minat tenaga kesehatan sehingga persoalan mengenai pemerataan tenaga kesehatan dapat diatasi.

Dalam menyelesaikan persoalan pemerataan tenaga kesehatan, pemerintah pada dasarnya telah melakukan berbagai upaya diantaranya pendayagunaan tenaga kesehatan di Instansi pemerintah baik pusat maupun daerah. Tenaga kesehatan yang didayagunakan di instansi pemerintah, utamanya di sektor kesehatan diangkat melalui formasi PNS baik pusat maupun daerah, pegawai tidak tetap/PTT pusat maupun daerah, penugasan khusus baik residen maupun tenaga D3-Kesehatan dan lainnya (Bappenas, 2005).

Namun pada kenyatannya, di lapangan masih didapatkan adanya kekurangan SDMK pada beberapa Kabupaten/Kota, apalagi bila dikaji lebih lanjut terdapat jumlah tenaga kesehatan 
yang terlalu banyak pada jenis tenaga kesehatan tertentu seperti Perawat dan Bidan, namun tidak diikuti oleh tenaga kesehatan lainnya. Seharusnya setiap Kabupaten/Kota mempunyai tenaga kesehatan yang sesuai dengan jumlah yang dibutuhkan oleh masing-masing penduduk pada tiap wilayah. Hal ini sesuai dengan peraturan mengenai jumlah minimal tenaga kesehatan pada beberapa fasilitas kesehatan seperti Puskesmas dan Rumah Sakit. Apabila setiap fasilitas kesehatan telah memenuhi jumlah tenaga minimal yang harus dimiliki pada tiap fasilitas kesehatan, maka diharapkan tenaga kesehatan dapat tersebar rata di setiap Kabupaten/Kota.

Pada keadaan demikian Dinas Kabupaten/Kota seharusnya mengkaji lagi terkait kurangnya tenaga kesehatan di wilayahnya. Agar kurangnya tenaga kesehatan tersebut dapat dilaporkan kepada Dinas Kesehatan Provinsi dalam bentuk penyusunan kebutuhan tenaga kesehatan, agar dari instansi terkait dapat ditindak lanjuti sesuai dengan prosedur dan ketetapan yang berlaku.

Proses perkiraan sumber daya manusia kesehatan (SDMK) di Dinas Kesehatan Provinsi Jawa Timur dilakukan dengan menghitung rasio jumlah penduduk dengan tenaga kesehatan. Menurut Kepmenkes No 81 Tahun 2004 metode rasio yang digunakan dalam menyusun rencana kebutuhan SDMK yaitu dengan membandingkan jumlah standar tenaga kesehatan terhadap jumlah penduduk di suatu wilayah dengan alasan paling cepat dan efektif mengingat adanya berbagai keterbatasan yang dihadapi seperti tenaga perencana yang tidak terlatih, data yang kurang lengkap, dan terbatasnya waktu perencanaan.

Sesuai dengan Kepmenkes No. 81/Menkes/SK/I/2004 tentang Pedoman Penyususnan Perencanaan Sumber Daya Manusia Kesehatan di Tingkat Propinsi, Kabupaten/Kota serta Rumah Sakit terutama dengan mengacu pada metode perhitungan tenaga kesehatan bersadarkan pendekatan rasio terhadap nilai tertentu, maka ditetapkan beberapa target untuk beberapa tahun kedepan.
Pada tahun 2014 diharapkan ketersediaan tenaga dokter spesialis mencapai 12 per 100.000 penduduk, dokter umum 48 per 100.000 , dokter gigi 11 per 100.000 penduduk, perawat 158 per 100.000 penduduk, bidan 75 per 100.000 penduduk, sanitarian 15 per 100.000 penduduk dan tenaga gizi 24 per 100.000 penduduk. Pada tahun 2019 diharapkan ketersediaan tenaga dokter spesialis mencapai 24 per 100.000 penduduk, dokter umum 96 per 100.000 , dokter gigi 11 per 100.000 penduduk, perawat 158 per 100.000 penduduk, bidan 75 per 100.000 penduduk, sanitarian 30 per 100.000 penduduk dan tenaga gizi 48 per 100.000 penduduk. Pada tahun 2025 diharapkan ketersediaan tenaga dokter spesialis mencapai 28 per 100.000 penduduk, dokter umum 112 per 100.000 , dokter gigi 11 per 100.000 penduduk, perawat 158 per 100.000 penduduk, bidan 75 per 100.000 penduduk, sanitarian 35 per 100.000 penduduk dan tenaga gizi 56 per 100.000 penduduk.

Tabel rasio jumlah sumber daya manusia kesehatan (SDMK) di Provinsi Jawa Timur dibandingkan dengan target sesuai Kepmenkes No. 81/Menkes/SK/I/2004 akan dapat dilihat pada gambar berikut :

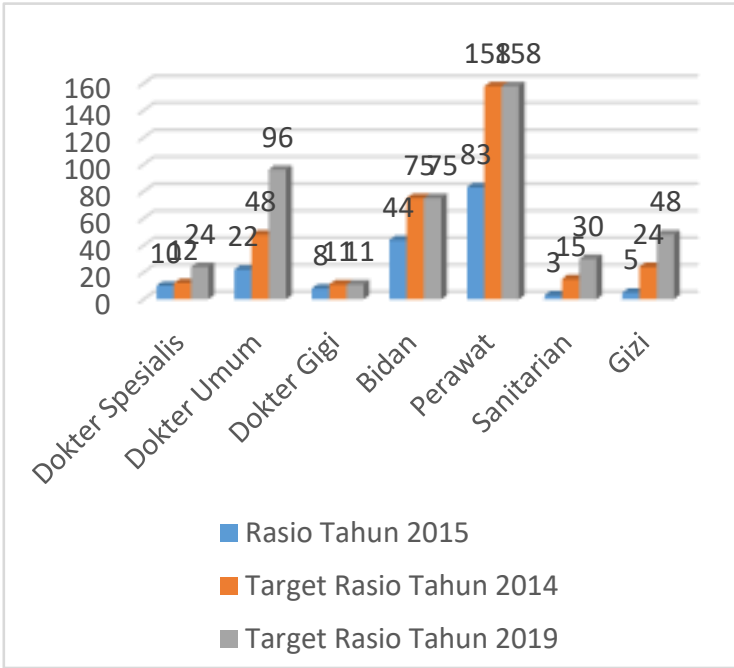

Gambar 11. Rasio sdmk tahun 2015 dengan target rasio Kepmenkes tahun 2014 dan Tahun 2019

Dari gambar 11 diatas, sebagian besar rasio sumber daya manusia kesehatan di Provinsi Jawa Timur masih dibawah target yang ditetapkan oleh Kepmenkes 
(2004), meski ada beberapa SDMK yang hampir mencapai target rasio pada tahun 2014 yaitu rasio dokter spesialis. Rasio yang dibawah target seharusnya menjadi pertimbangan dalam membuat kebijakan terkait tenaga kesehatan, bagi pemerintah dan institusi terkait dalam melakukan pendayagunaan tenaga kesehatan. Selain itu perencanaan kebutuhan tenaga kesehatan masih perlu ditingkatkan dan didukung dengan sistem informasi tenaga kesehatan yang memadai (Guspianto, 2014).

Rencana kebutuhan yang dilakukan baik di tingkat Kabupaten/Kota ataupun Propinsi belum disusun sesuai yang diharapkan, sehingga belum sepenuhnya dapat digunakan sebagai acuan dalam pengadaan tenaga kesehatan, pendayagunaan tenaga kesehatan serta pembinaan dan pengawasan mutu tenaga kesehatan. Begitupula dengan sistem informasi tenaga kesehatan yang belum juga sepenuhnya dapat menyediakan data akurat, terpercaya dan tepat waktu (Ilyas, 2004).

Berdasarkan rasio sumber daya manusia kesehatan (SDMK) di Provinsi Jawa Timur tahun 2015 beserta target SDMK dari Kepmenkes tahun 2014, sebanyak $\quad 18,42 \% \quad$ Kabupaten/Kota mempunyai rasio dokter spesialis diatas target; $\quad 15,78 \% \quad$ Kabupaten/Kota mempunyai rasio dokter umum diatas target; 5,26\% Kabupaten/Kota mempunyai rasio bidan diatas target; 23,68\% Kabupaten/Kota mempunyai rasio perawat diatas target; $18,42 \%$ Kabupaten/Kota mempunyai rasio tenaga gizi diatas target; $15,78 \%$ Kabupaten/Kota mempunyai rasio tenaga farmasi diatas target dan 28,94\% Kabupaten/Kota mempunyai rasio tenaga kesmas diatas target. Apabila dikaji lebih lanjut, sebanyak 84,22\% Kabupaten yang belum memeuhi target rasio dokter umum harus menaikkan rasio dokter umum sebanyak 2 sampai 3 kali lipat untuk bisa berada diatas target. Begitupula untuk jenis tenaga kesehatan lainnya, harus menaikkan beberapa kalilipat agar target rasio terpenuhi.

Kabupaten/Kota yang mempunyai rasio tenaga kesehatan diatas target diharapkan dapat dipertahankan dengan berbagai cara. Misalnya dengan memenuhi hak - hak tenaga kesehatan tersebut antara lain meliputi kesejahteraan dan kesempatan yang seluas - luasnya dalam rangka meningkatkan dan mengembangkan karirnya yang dapat meningkatkan kualitas dari diri tenaga kesehatan tersebut, mengingat masih memungkinkan tenaga kesehatan melakukan mutasi ke Kabupaten/Kota lainnya dengan berbagai alasan. Sehingga Kabupaten/Kota akan mengalami kekurangan tenaga kesehatan. Hal ini sesuai dengan teori yaitu Instansi harus mendukung pegawainya untuk mengembangkan karir mereka karena hal ini sangat vital dalam menjaga loyalitas. Atasan harus berusaha membantu pegawai untuk bekerja seefektif mungkin dan menciptakan iklim kerja yang memungkinkan tercapainya pengembangan karir dan kepuasan kerja (Rachmawati, 2008). Dengan terjaganya loyalitas dari tenaga kerja diharapkan dapat meningkatkan pelayanan kesehatan yang diberikan kepada masyarakat.

Kabupaten/Kota yang mempunyai rasio tenaga kesehatan dibawah target, diharapkan bagi instansi terkait yaitu Dinas Kesehatan Provinsi melakukan pendayagunaan tenaga kesehatan meliputi penyebaran tenaga kesehatan yang merata dan berkeadilan dan pemanfaatan tenaga kesehatan, melanjutkan program pemerintah yang bertujuan untuk meningkatkan ketersediaan SDMK bagi daerah tertinggal melalui program pemberian insentif keuangan yang lebih besar dan periode kontrak yang lebih pendek, rekrutmen berdasarkan etnis dan lokasi, dan program magang (Bapenas, 2014). Selain itu, diharapkan Kabupaten/Kota perlu meningkatkan perencanaan tenaga kesehatan yang sesuai dengan kebutuhannya.

\section{SIMPULAN DAN SARAN}

\section{Simpulan}

Jumlah SDMK di Jawa Timur tahun 2015 paling banyak adalah dokter, bidan dan perawat. SDMK lebih banyak didapatkan di kota - kota besar seperti Kota 
Surabaya, Kota Malang dan Kabupaten Sidoarjo sedangkan di Kabupaten Ngawi, Kabupaten Sumenep dan Kabupaten Bondowoso tenaga kesehatan jumlahnya cenderung lebih sedikit. Rasio SDMK pada tahun 2015 masih dibawah target Kepmenkes meski terdapat beberapa jenis SDMK yang mendekati target rasio dari Kepmenkes.

\section{Saran}

Bagi instansi terkait diharapkan dapat mengoptimalkan upaya pemerataan sumber daya manusia kesehatan (SDMK) di kabupaten/kota agar distribusinya dapat merata sehingga diharapkan dapat meningkatkan pelayanan kesehatan terhadap masyarakat.

\section{DAFTAR PUSTAKA}

A. A. Anwar. 2009. Perencanaan dan Pengembangan Sumber Daya Manusia. Jakarta : Refika Aditama

Dinas Kesehatan Provinsi Jawa Timur. Profil Kesehatan Provinsi Jawa Timur Tahun 2015. Surabaya: Dinas Kesehatan Provinsi Jawa Timur.

Grace A. Salamate, A.J.M. Rattu, J.N.Pangemanan. Analisis Perencanaan Sumber Daya Manusia Kesehatan di Dinas Kesehatan Kabupaten Minahasa Tenggara. Artikel Penelitian. JIKMU, Suplemen Vol. 4, No. 4, Oktober 2014. Tersedia di http://ejournal.unsrat.ac.id/index.ph p/jikmu/article/download/7683/724 9. [disitasi tanggal 9 September 2016].

Guspianto. 2012. Analisis Penyusunan Rencana Kebutuhan SumberDaya Manusia (SDM) Kesehatan Puskesmas Di Kabupaten Muaro Jambi. Prosidng Seminar Nasional Kesehatan. Jurusan Kesehatan Masyarakat FKIK UNSOED. Tersedia di kesmas.unsoed.ac.id [disitasi tanggal 11 September 2016].

Rasul dan Hasanbasri. 2007. Kecukupan dan Kesesuaian Tenaga Kesehatan di Kabupaten Solok Selatan. Paper.
KMPK Universitas Gadjah Mada, Yogyakarta.

Ilyas, Yaslis. 2004. Perencanaan SDM Rumah Sakit; Teori, Metoda dan Formula. Pusat Kajian Ekonomi Kesehatan FKM-UI Jakarta.

Kajian Sektor Kesehatan. Kementrian PPN/Bappenas : 2014.

KA. Pusrengun SDM Kesehatan. 2014. Kajian Standar Kebutuhan SDM Kesehatan di Fasyankes.

Kepmenkes RI Nomor 81/Menkes/SK/I/2004 Tentang Pedoman Penyusunan Perencanaan Sumber Daya Manusia Kesehatan di Tingkat Propinsi, Kabupaten/Kota serta Rumah Sakit. Jakarta : Kepmenkes RI.

Kurniawati, A dan F. Effendi. 2012. Kajian SDMK di Indonesia. Jakarta : Salemba Medika.

Manuallang. 2008. Manajemen Sumber Daya Manusia. Yogyakarta : BPFE

Nina Sardjunani. Tantangan Pembangunan Kesehatan Tahun 2015 - 2019. Deputi Bidang SDM dan Kebudayaan, Bappenas. Jakarta : 2015.

Peraturan Daerah Provinsi Jawa Timur Nomor 7 Tahun 2014 Tentang Tenaga Kesehatan. Surabaya : 2014

Pungkas Bahjuri Ali, Dadang Rizki Ratman, Sularsono. Kajian Kebijakan Perencanaan Tenaga Kesehatan. Direktorat Kesehatan dan Gizi Masyarakat. Bappenas : 2005.

Rachmawati, IK. 2008. Manajemen Sumber Daya Manusia. Jakarta : Rineka Cipta

Rencana Pengembangan Tenaga Kesehatan Tahun 2011 - 2025. Jakarta : 2011.

Soekidjo Notoatmodjo. 2008. Kesehatan dan Pembangunan Sumber Daya Manusia. Jurnal Kesmas Nasional Vol. 2, No. 5, April 2008. Tersedia di

http://download.portalgaruda.org/ar ticle.php? article $=269783 \& \mathrm{val}=713$ \&title $=$ kesehatan $\% 20$ dan $\% 20$ pemb angunan $\% 20$ sumber\%20daya $\% 20$ 
JURNAL ILMIAH KESEHATAN MEDIAHUSADA | VOLUME 07/NOMOR 01/MARET 2018

manusia.[disitasi tanggal 11

September 2016). 